\title{
Sexual selection in genetic colour-polymorphic species: a review of experimental studies and perspectives
}

\author{
Alexandre Roulin · Pierre Bize
}

Received: 6 March 2006/ Accepted: 12 June 2006/Published online: 19 July 2006

(C) Japan Ethological Society and Springer-Verlag 2006

\begin{abstract}
Sexual selection theory has primarily focussed on the role of mating preferences for the best individuals in the evolution of condition-dependent ornaments, traits that signal absolute quality. Because the most suitable mate for one individual is not always the best for others, however, we argue that nondirectional mate choice can promote the evolution of alternative morphs that are not condition-dependent in their expression (i.e. genetic polymorphism). We list the different mate-choice rules (i.e. all individuals have the same preference; preference depends on the chooser's morph; individuals mate preferentially with conspecifics displaying an uncommon or the most frequent morph) and review experimental studies that investigated mate choice in natural populations of colour-polymorphic animals. Our review emphasises that although the experimental data support the idea that sexual selection plays an important role in the evolution of genetic colour polymorphism in many different ways, little is known about the adaptive value of each mate-choice strategy and about their implication in the evolutionary stability of colour polymorphism. One way of solving this problem is to determine the adaptive function of colour morphs, a worthwhile objective, because better understanding of mate-choice
\end{abstract}

\footnotetext{
A. Roulin $(\square)$

Department of Ecology and Evolution,

University of Lausanne, Biology Building,

Lausanne 1015, Switzerland

e-mail: Alexandre.Roulin@unil.ch

P. Bize

Division of Environmental and Evolutionary Biology,

IBLS, Graham Kerr Building, Glasgow University,

Glasgow G12 8QQ, UK
}

rules in polymorphic species should provide important insights into sexual-selection processes and, in turn, into the maintenance of genetic variation.

Keywords Alternative strategies - Conditiondependence - Genetic colour polymorphism - Mate choice $\cdot$ Polymorphism $\cdot$ Sexual selection

\section{Introduction}

Since Zahavi (1975) proposed the handicap principle stipulating that ornaments can signal honestly individual quality, for example the ability to fend off diseases, body condition, reproductive success, and survival prospects (reviewed by Johnstone 1995) only if they entail production and wearing costs, evolutionary biologists have traditionally considered conditiondependent ornaments when studying sexual-selection processes. Because condition-dependent ornaments entail significant costs to their bearer, the handicap principle predicts that only high-quality males can afford to pay these costs (Cotton et al. 2004) and, as a consequence, that sexual selection is directional, with females pairing and mating preferentially with ornamented males. If the handicap principle provides a clear explanation of how sexual dimorphism in ornamental traits can evolve and be maintained, it is less obvious how genetic variation is maintained despite episodes of strong directional sexual selection for the most ornamented males (Kotiaho et al. 2001).

Not all inter-individual variation in shape and colouration observed in nature is condition-dependent. In many species individuals belonging to a same population display one of several morphs that are under 
strong genetic control (insects: Majerus 1998; spiders: Oxford and Gillespie 1998; anurans: Hoffman and Blouin 2000; molluscs: Goodhart 1987; reptiles: Shine et al. 1998; mammals: Majerus and Mundy 2003; birds: Roulin 2004; plants: Warren and Mackenzie 2001). The handicap principle cannot be applied to the study of sexual selection in genetic polymorphic species, however, because the maintenance of several genetically inherited morphs within populations implies that the display of alternative morphs provides similar net benefits. Although the costs and benefits of displaying morphs can be different, genetic polymorphism is evolutionarily stable when the balance between these costs and benefits is equal, and in that case morphs can be regarded as equally rewarding alternative strategies (Maynard-Smith 1982). For this reason, in genetically polymorphic species sexual selection may be directional only under restricted conditions. Females may, therefore, often use other mate-choice rules to select a mate, rules that can differ between species, populations, or even between individuals (Burley 1983; Endler and Houde 1995).

Our objective in this paper is to present the different mate-choice rules of polymorphic animals and to explain how these rules can be compatible with the maintenance of polymorphism. As our paper shows, most of these mate-choice rules have not yet been firmly demonstrated, and hence an objective of our paper is to stimulate experimental studies. Because sexual selection studies have been primarily conducted to explain the evolution of colourful traits, we have based our review on genetic colour-polymorphic species. The review is, however, built in such a way that the concepts are applicable to other types of polymorphic trait.

\section{Definition of genetically polymorphic phenotypes}

A species has genetically polymorphic phenotypes when individuals of the same age and the same sex in a population display one of several morphs that are genetically inherited and for which expression is not, or is to a negligible extent, sensitive to the environment and to body condition. Genetic polymorphic traits can therefore be regarded as "condition-independent". Genetic polymorphism does not include species for which inter-individual phenotypic variation is because of a seasonal and reversible change in the phenotype (e.g. the white or brown plumage produced by rock ptarmigans, Lagopus mutus, in winter and spring, respectively; Montgomerie et al. 2001), because of a seasonal and irreversible change in the phenotype (e.g. red or black wing patterns produced in the map butterfly, Araschnia levana, in the first and second generation, respectively; Fric and Konvicka 2002), or because of environmentally mediated change in the phenotype (e.g. small or large horn size in beetles; Moczek 1998). The production of environmentally mediated discontinuous morphs is referred to as polyphenism (Nijhout 2003). For brevity, from now on we denote "genetic colour polymorphism" as "polymorphism".

\section{Mate-choice rules in polymorphic species}

All individuals have the same preference

A colour polymorphism is evolutionarily stable if one morph has no selective advantage over other morphs. This key assumption implies that in evolutionarily stable colour-polymorphic species sexually active individuals can have the same preference for a particular colour morph in one of four non-exclusive scenarios.

1 Directional sexual selection varies temporarily. A directional preference for one morph should be exerted only temporarily otherwise the polymorphism is transient (Ford 1945) with directional sexual selection facilitating the introgression of one morph into another. Directional sexual selection may occur during a short period of time only, for instance when the most preferred morph is suddenly locally adapted to specific environmental or social factors. In other words, at some point in time individuals prefer to mate with morph $\mathrm{A}$ and later they prefer to mate with morph $\mathrm{B}$ or have no preference. Experimental evidence for temporal variation in directional sexual selection has been reported in ladybird beetles Harmonia asyridis. In this species, mate choice varies depending on prevailing environmental factors, with females having a preference for non-melanic males in spring but for melanic males in the summer (Osawa and Nishida 1992). Because it is usually thought that temporarily fluctuating selection on phenotype can hardly maintain genetic variance (Hedrick 1986; Barton and Turelli 1989; but see Ellner and Hairston 1994), more studies are required to determine how colour polymorphism is maintained in species like the ladybird beetle.

2 Directional sexual selection varies spatially. Individuals from different populations should have a 
strong preference for alternate morphs (in population $\mathrm{A}$ individuals mate preferentially with morph A and in population B with morph B). Immigration between populations of each other's selected morph may help maintain colour polymorphism (Lawson 1996; Merilaita 2001). Alternatively, morphs may be specialised in the exploitation of different niches or habitats (Skúlason and Smith 1995) and each of these morphs may be preferred as mates in the environment in which they are locally adapted (Frank and Slatkin 1990). Accordingly, mate-choice experiments in two populations of the fish pygmy swordtail Xiphophorus pygmaeus demonstrated that females preferred to mate with blue rather than with yellow males, whereas no consistent preference was found in a third population. The use of optical filters to modify colouration showed that the female preference for blue males is because of an aversion to yellow males (Kingston et al. 2003). This study suggests that a directional female preference for a male morph is not necessarily consistent across populations. Future work should focus on among-population variation in the strength of a preference and on the role of dispersal in maintaining colour polymorphism despite directional selection.

3 Morphs are associated with alternative mating strategies. The less preferred morph may use a strategy other than attractiveness to equalise fitness with the most preferred morph (Gross 1996). For example, one morph may be less attractive but more competitive than another, resulting in equal mating success (Kingston et al. 2003; see also Cook et al. 1994). In other words, different components of sexual selection (i.e. intersexual vs intrasexual competition) may be traded-off against each other, and the morphs may therefore be regarded as alternative reproductive strategies (e.g. Lank et al. 1995; Sinervo and Lively 1996). Although it has frequently been proposed that colour polymorphism is associated with alternative mating strategies, very few empirical studies have been reported in the literature. Perhaps the most famous studies are those of the ruff, Philomachus pugnax, with differently coloured males adopting different genetically inherited mating behaviour (Lank et al. 1995): dark males have a territorial breeding tactic of defending lek mating courts against white males that adopt sneaky behaviour to copulate. In five butterfly populations of the clouded sulfur Colias philodice, males were attracted by yellow rather than melanic females; this resulted in higher mating success of the yellow morph. The finding that yellow females have a mating advantage throughout their elevational range (tests were conducted between 1,840 and $2,920 \mathrm{~m}$ asl), even though wing melanisation provides thermal benefits at high altitude but increases the risk of overheating at low altitude, suggests that yellow and melanic morphs are alternative mating strategies (Ellers and Boggs 2002). In the sockeye salmon Oncorhynchus nerka, the olive green kokanee morph lives in freshwater environments where the availability of carotenoids is lower than in marine environments, where the red sockeye also occurs. Females of both morphs were experimentally shown to mate preferentially with red males suggesting that red and kokanee morphs use alternative but equally rewarding mating strategies (Craig and Foote 2001), unless the polymorphism is transient. This study is interesting because directional sexual selection is exerted on a polymorphism that determines the efficiency of use of carotenoids, pigments that participate in the elaboration of condition-dependent red colouration in many organisms (Olson and Owens 1998). A similar finding has been reported for the pentamorphic livebearing fish Poecilia parae, in which females preferred red and yellow males to blue and non-coloured males (Bourne et al. 2003). Clearly more studies are needed to determine how morphs equalise fitness despite directional sexual selection.

4 Sexual selection is antagonistically exerted in the two sexes. Although morphs are found in the two sexes, females may prefer to mate with males displaying a given morph whereas males may have a preference for females displaying another morph (Price and Burley 1994). This situation may occur if morphs are sex-specific ornaments with one morph being associated with female-specific qualities and another morph with male-specific qualities (Roulin et al. 2001). We are aware of only one experimental study consistent with antagonistic sexual selection. In laboratory choice tests performed with the white-throated sparrow Zonotrichia albicollis, in which a chromosomal inversion generates a colour polymorphism (Thorneycroft 1966), females of both morphs mated preferentially with tan-striped rather than white-striped males. In contrast, males of both morphs were more attracted by whitestripped females (Houtman and Falls 1994). The possibility that sex-specific preference for alternative morphs helps maintain colour polymorphism in the face of directional mate choice should be investigated further. 
Preference depends on the chooser's morph

Three major mechanisms can promote the evolution of mate choice strategies that depend on the chooser's morph. More specifically, two individuals differ in their mate-choice preference because they are not similarly coloured.

1 Assortative mating as an indirect result of allopatric isolation. When a geographic barrier divides a population in two a novel colouration may evolve in one of the two populations, and a preference for it. When the two populations meet in a zone of secondary contact, similarly coloured individuals will tend to breed together because of morph-specific pre-mating behaviour that evolved in allopatry, as shown for the herring/lesser black-backed gulls Larus argentatus and L. fuscus (Harris 1970), the colour-polymorphic snow goose Anser caerulescens (Cooke and Davies 1983) and the fly Drosophila elegans (Ishii et al. 2001). Although prezygotic isolation results in assortative pairing with respect of colour morph and, ultimately, in speciation, with morphs becoming separate species (Kondrashow and Shpak 1998), assortative pairing may not necessarily have an adaptive function but be a byproduct of allopatric isolation (Cooke et al. 1975). In the snow goose, for example, reproductive success of similarly coloured breeding partners was not greater than that of pairs composed of dissimilar mates (Findlay et al. 1985).

2 Assortative mating for genetic compatibility or homozygous benefits. Individuals mate preferentially with conspecifics displaying the same colour morph if similarly coloured individuals are genetically more compatible than dissimilarly coloured individuals or if there is an advantage of producing offspring that are homozygous at genes coding for colouration or at closely linked genes. In species in which pairing is usually assortative, similarly coloured partners should achieve greater reproductive success than dissimilarly coloured partners, as shown for carrion crows, Corvus corone, and hooded crows, C. cornix (Saino and Villa 1992). In such species with strong assortative pairing, colour polymorphism should be transient or restricted to hybrid zones (e.g. Parkin et al. 2003).

3 Disassortative mating to avoid inbreeding or for heterozygous benefits. Individuals may prefer to mate with dissimilarly coloured conspecifics if colour polymorphism is a criterion enabling avoidance of inbreeding or production of heterozygous offspring. This type of mate choice has not been yet demonstrated experimentally, even though disassortative pairing occurs in many polymorphic species (in six out of twenty-four polymorphic bird species, 25\%; Roulin 2004).

Individuals mate preferentially with conspecifics displaying an uncommon morph

When a morph derives fitness benefits because it occurs at low frequency, selection is referred to as "negative frequency-dependent". This selection mode is cited as a key mechanism in maintaining genetic variation in natural populations (Ayala and Campbell 1974). In colour-polymorphic species individuals displaying a rare morph may often enjoy a mating advantage over those exhibiting a common morph. By mating with a rare morph females may produce heterozygous or outbred offspring, an aspect that has not yet been tackled. The fitness benefit derived from this matechoice rule (Kelly et al. 1999) should be large enough to compensate for the cost of finding and monopolising a mate displaying a rare but attractive phenotype.

In the guppy Poecilia reticulata, but not in the Gouldian finch Erythrura gouldiae (Fox et al. 2002), females were more sexually responsive toward males introduced into a laboratory population if the new males bore colour patterns not present in males already in the population (Farr 1977). Novelty rather than rarity of these newly introduced males explained their mating success, however (Hughes et al. 1999; Eakley and Houde 2004). It therefore remains unclear whether morphs can be preferred only when rare, an aspect that has been demonstrated in polymorphic plants (Gigord et al. 2001). A proper experimental test requires that each morph is, in turn, the rarest, with the prediction that only then is that morph sexually attractive.

Individuals mate preferentially with conspecifics displaying the most frequent morph

The case where a morph derives a mating advantage when abundant is puzzling, because genetic variation may be quickly depleted with, as a result, a colourpolymorphic species evolving toward a monomorphic colour state. Nevertheless this mate-choice rule may prevail in an evolutionarily stable colour-polymorphic species if the most common morph is not the same in all populations. Loss of genetic variation because of mate choice would be replenished by immigration of morphs between populations. 
A firm conclusion for the hypothesis that mate choice favours the most common morph requires the demonstration that in a same population morph $\mathrm{A}$ is preferred to morph $\mathrm{B}$ when morph $\mathrm{A}$ is more abundant than morph $\mathrm{B}$, and the other way round when morph $\mathrm{B}$ is more frequent than morph $\mathrm{A}$. We are aware of no study that has used such an experimental approach. The best example suggesting some role of abundance in mate-choice decision is that of odonates in which females appear in two morphs, androchrome (i.e. male-like females) and gynochrome (i.e. femalespecific colouration). In this insect group, colour polymorphism is frequent ( $43 \%$ of the species; Cordero and Andrés 1996) and both intra-specific and inter-specific studies showed that males mate preferentially with the most abundant female morph (van Gossum et al. 1999). Two experimental studies pointed out that males mate preferentially with the morph they experienced most recently (Miller and Fincke 1999; van Gossum et al. 2001) suggesting that males prefer females displaying the most common morph because they learn to recognise it more quickly than the less abundant morph. This mate-choice rule may enable males to reduce the cost of searching for mates. This statement is based on the observation that when gynochrome females are abundant, males neglect andromorphic females, probably because they are hardly distinguishable from males (Cordero et al. 1998; Andrés et al. 2002). In contrast, when androchrome is the most prevalent female morph, males mate with all individuals to avoid missing potential copulations (van Gossum et al. 1999).

\section{Conclusions and perspectives}

Two conclusions can be drawn from our review. First, and in contrast with species displaying conditiondependent ornaments, the study of polymorphic species emphasises that mate choice is not necessarily unidirectional. We use the word "unidirectional" to indicate that the same directional mate choice is exerted in all environments, irrespective of the chooser's phenotype or genotype, and remains the same through time. This terminology is important because short-term studies performed in a single environment may demonstrate that most females have the same preference for ornamented males, suggesting that sexual selection is always directional. Such studies cannot, however, rule out the possibility that the magnitude and sign of the preference vary among habitats and social environments, with time, between populations, and within individuals (Qvarnström et al. 2000; van Gossum et al.
2001; Brooks 2002). Mating preferences can indeed be context-dependent rather than fixed if morphs are adapted to local factors (genotype by environment interactions) with all individuals having a preference for the locally adapted morphs. Short-term studies reporting directional mate choice should therefore be repeated at different times, in several populations (Rolán-Alvarez et al. 1999), and also under different ecological and social conditions to test if a directional preference for one morph can switch to another morph after a sudden change in environmental or social factors (Alonzo and Sinervo 2001). The study of mate choice in polymorphic species is, therefore, likely to provide a better understanding of the role of the interaction between genetics and ecology in the evolution of sexual-selection processes and, in turn, in the maintenance of genetic variation.

Second, almost nothing is known about the benefits of adopting one mate-choice rule or another. This situation prevails because the adaptive function of alternative morphs is usually unknown. Experimental data are therefore required to test whether, by mating with a given morph, choosy individuals derive homozygote or heterozygote advantages, whether such a preference facilitates inbreeding avoidance, or whether mate choice is selectively neutral. In this context, a conceptual framework to identify which physiological, morphological, and behavioural attributes should consistently differ between alternative morphs would be extremely useful to generate predictions regarding mate-choice rules adopted under specific environmental or social conditions. In the future this will be the greatest challenge in exploration of the evolution and maintenance of genetic colour polymorphism.

Acknowledgments Julien Gasparini, Jérôme Goudet, and two anonymous referees provided useful comments on a earlier version of the text. The Swiss Science Foundation financed this work (grant n PP00A-102913 to AR and PPOOA-109009 to PB).

\section{References}

Alonzo SH, Sinervo B (2001) Mate choice games, contextdependent good genes, and genetic cycles in the side-blotched lizard, Uta stansburiana. Behav Ecol Sociobiol 49:176186

Andrés JA, Sánchez-Guillén RA, Cordero Rivera A (2002) Evolution of female colour polymorphism in damselflies: testing the hypotheses. Anim Behav 63:677-685

Ayala FJ, Campbell CA (1974) Frequency-dependent selection. Annu Rev Ecol Syst 5:115-138

Barton NH, Turelli M (1989) Evolutionary quantitative genetics: how little do we know. Annu Rev Genet 23:337-370

Bourne GR, Breden F, Allen JA (2003) Females prefer carotenoid colored males as mates in the pentamorphic livebearing fish, Poecilia parae. Naturwissenschaften 90:402-405 
Brooks R (2002) Variation in female mate choice within guppy populations: population divergence, multiple ornaments and the maintenance of polymorphism. Genetica 116:343-358

Burley N (1983) The meaning of assortative mating. Ethol Sociobiol 4:191-203

Cook SE, Vernon JG, Bateson M, Guilford T (1994). Mate choice in the polymorphic African swallowtail butterfly, Papilio dardanus: male-like females may avoid sexual harassment. Anim Behav 47:389-397

Cooke F, Davies JC (1983) Assortative mating, mate choice and reproductive fitness in show geese. In: Bateson $\mathrm{P}$ (eds) Mate choice. Cambridge University Press, Cambridge pp 279-295

Cooke F, MacInnes CD, Prevett JP (1975) Gene flow between breeding populations of lesser snow geese. Auk 92:493-510

Cordero A, Andrés JA (1996) Colour polymorphism in odonates: females that mimic males? J Brit Dragonfly Soc 12:50-60

Cordero A, Carbone SS, Utzeri C (1998) Mating opportunities and mating costs are reduced in androchrome female damselflies, Ischnura elegans (Odonata). Anim Behav 55:185-197

Cotton S, Fowler K, Pomiankowski A (2004) Do sexual ornaments demonstrate heightened condition-dependent expression as predicted by the handicap hypothesis. Proc Biol Sci B271:771-783

Craig JK, Foote CJ (2001) Countergradient variation and secondary sexual color: phenotypic convergence promotes genetic divergence in carotenoid use between sympatric anadromous and nonanadromous morphs of sockeye salmon (Oncorhynchus nerka). Evolution 55:380-391

Eakley AL, Houde AE (2004) Possible role of female discrimination against 'redundant' males in the evolution of colour pattern polymorphism in guppies. Proc Biol Sci 271:299-301

Ellers J, Boggs CL (2002) The evolution of wing color in Colias butterflies: heritability, sex linkage, and population divergence. Evolution 56:836-840

Ellner S, Hairston NG (1994) Role of overlapping generations in maintaining genetic variation in a fluctuating environment. Am Nat 143:403-417

Endler JA, Houde AE (1995) Geographic variation in female preferences for male traits in Poecilia reticulata. Evolution 49:456-468

Farr JA (1977) Male rarity or novelty, female choice behavior, and sexual selection in the guppy, Poecilia reticulata Peters (Pisces: Poeciliidae). Evolution 31:162-168

Findlay CS, Rockwell RF, Smith JA, Cooke F (1985) Life history studies of the lesser snow goose (Anser caerulescens caerulescens) VI. Plumage polymorphism, assortative mating and fitness. Evolution 39:904-914

Ford EB (1945) Polymorphism. Biol Rev 20:73-88

Fox S, Brooks R, Lewis MJ, Johnson CN (2002) Polymorphism, mate choice and sexual selection in the Gouldian finch (Erythrura gouldiae). Aust J Zool 50:125-134

Frank SA, Slatkin M (1990) Evolution in a variable environment. Am Nat 136:244-260

Fric Z, Konvicka M (2002) Generations of the polyphenic butterfly Araschnia levana differ in body design. Evol Ecol Res 4:1017-1032

Gigord LDB, Macnair MR, Smithson A (2001) Negative frequency-dependent selection maintains a dramatic flower color polymorphism in the rewardless orchid Dactylorhiza sambucina (L.) Soò. Proc Natl Acad Sci USA 98:6253-6255

Goodhart CB (1987) Why are some snails visibly polymorphic, and others not? Biol J Linn Soc 31:35-58

Gross MR (1996) Alternative reproductive strategies and tactics: diversity within sexes. Trends Ecol Evol 11:92-98
Harris MP (1970) Abnormal migration and hybridization of Larus argentatus and $L$. fuscus after interspecies fostering experiments. Ibis 112:488-498

Hedrick PW (1986) Genetic polymorphism in heterogenous environments: a decade later. Annu Rev Ecol Syst 17:535566

Hoffman EA, Blouin MS (2000) A review of colour and pattern polymorphisms in anurans. Biol J Linn Soc 70:633-665

Houtman AM, Falls JB (1994) Negative assortative mating in the white-throated sparrow, Zonotrichia albicollis: the role of mate choice and intra-sexual competition. Anim Behav 48:377-383

Hughes KA, Du L, Rodd FH, Reznick DN (1999) Familiarity leads to female mate preference for novel males in the guppy, Poecilia reticulata. Anim Behav 58:907-916

Ishii K, Hirai Y, Katagiri C, Kimura MT (2001) Sexual isolation and cuticular hydrocarbons in Drosophila elegans. Heredity 87:392-399

Johnstone RA (1995) Sexual selection, honest advertisement and the handicap principle: reviewing the evidence. Biol Rev 70:1-65

Kelly JL, Graves JA, Magurran AE (1999) Familiarity breeds contempt in guppies. Nature 401:661-662

Kingston JJ, Rosenthal GG, Ryan MJ (2003). The role of sexual selection in maintaining a colour polymorphism in the pygmy swordtail, Xiphophorus pygmaeus. Anim Behav 65:735-743

Kondrashow AS, Shpak M (1998) On the origin of species by means of assortative mating. Proc R Soc Lond B265:22732278

Kotiaho JS, Simmons LW, Tomkins JL (2001) Towards a resolution of the lek paradox. Nature 410:684-686

Lank DB, Smith CM, Hanotte O, Burke T, Cooke F (1995) Genetic polymorphism for alternative mating behaviour in lekking male ruff Philomachus pugnax. Nature 378:59-62

Lawson R (1996) Gene flow and melanism in Lake Erie garter snake populations. Biol J Linn Soc 59:1-19

Majerus MEN (1998) Melanism, evolution in action. Oxford University, Oxford

Majerus MEN, Mundy NI (2003) Mammalian melanism: natural selection in black and white. Trends Genet 19:585-588

Maynard-Smith J (1982) Evolution and the theory of games. Cambridge University, Cambridge

Merilaita S (2001) Habitat heterogeneity, predation and gene flow: colour polymorphism in the isopod, Idotea baltica. Evol Ecol 15:103-116

Miller MN, Fincke OM (1999) Cues for mate recognition and the effect of prior experience on mate recognition in Enallagma damselflies. J Insect Behav 12:801-814

Moczek AP (1998) Horn polyphenism in the beetle Onthophagus Taurus: larval diet quality and plasticity in parental investment determine adult body size and horn morphology. Behav Ecol 9:636-641

Montgomerie R, Lyon B, Holder K (2001) Dirty ptarmigan: behavioural modification of conspicuous male plumage. Behav Ecol 12:429-438

Nijhout HF (2003) Development and evolution of adaptive polyphenisms. Evol Dev 5:9-18

Olson VA, Owens IPF (1998) Costly sexual signals: are carotenoids rare, risky or required? Trends Ecol Evol 13:510-514

Osawa N, Nishida T (1992) Seasonal variation in elytral colour polymorphism in Harmonia asyridis (the ladybird beetle): the role of non-random mating. Heredity 69:297-307

Oxford GS, Gillespie RG (1998) Evolution and ecology of spider coloration. Annu Rev Entomol 43:619-643 
Parkin DT, Collinson M, Helbig AJ, Knox AG, Sangster G (2003) The taxonomic status of carrion and hooded crows. Br Birds 96:274-290

Price DK, Burley NT (1994) Constraints on the evolution of attractive traits: selection in male and female zebra finches. Am Nat 144:908-934

Qvarnström A, Pärt T, Sheldon BC (2000) Adaptive plasticity in mate preference linked to differences in reproductive effort. Nature 405:344-347

Rolán-Alvarez E, Erlandsson J, Johannesson K, Cruz R (1999) Mechanisms of incomplete prezygotic reproductive isolation in an intertidal snail: testing behavioural models in wild populations. J Evol Biol 12:879-890

Roulin A (2004) The evolution, maintenance and adaptive function of genetic colour polymorphism in birds. Biol Rev 79:815-848

Roulin A, Riols C, Dijkstra C, Ducrest A-L (2001) Female- and male-specific signals of quality in the barn owl. J Evol Biol 14:255-267

Saino N, Villa S (1992). Pair composition and reproductive success across a hybrid zone of carrion crows and hooded crows. Auk 109:543-555
Shine R, Ambariyanto, Harlow PS, Mumpuni (1998) Ecological divergence among sympatric colour morphs in blood pythons, Python brongersmai. Oecologia 116:113-119

Sinervo B, Lively CM (1996) The rock-paper-scissors game and the evolution of alternative male strategies. Nature 380:240-243

Skúlason S, Smith TB (1995) Resource polymorphisms in vertebrates. Trends Ecol Evol 10:366-370

Thorneycroft HB (1966) Chromosomal polymorphism in the white-throated sparrow Zonotrichia albicollis (Gmelin). Science 154:1571-1572

Van Gossum H, Stoks R, Matthysen E, Valck F, de Bruyn L (1999) Male choice for female colour morphs in Ischnura elegans (Odonata, Coenagrionidae): testing the hypotheses. Anim Behav 57:1229-1232

Van Gossum H, Sotks R, de Bruyn L (2001) Reversible frequency-dependent switches in male mate choice. Proc Biol Sci B268:83-85

Warren J, Mackenzie S (2001) Why are all colour combinations not equally represented as flower colour polymorphisms? New Phytol 151:237-241

Zahavi A (1975) Mate selection-a selection for a handicap. J Theor Biol 53:205-214 